\title{
Mesenchymal stromal cell treatment prevents H9N2 avian influenza virus- induced acute lung injury in mice
}

Yan $\mathrm{Li}^{1,2+}$, Jun $\mathrm{Xu}^{3+}$, Weiqing Shi ${ }^{3}$, Cheng Chen ${ }^{1}$, Yan Shao ${ }^{1}$, Limei Zhu', Wei Lư ${ }^{1 *}$ and XiaoDong Han²*

\begin{abstract}
Background: The avian influenza virus (AIV) can cross species barriers and expand its host range from birds to mammals, even humans. Avian influenza is characterized by pronounced activation of the proinflammatory cytokine cascade, which perpetuates the inflammatory response, leading to persistent systemic inflammatory response syndrome and pulmonary infection in animals and humans. There are currently no specific treatment strategies for avian influenza.

Methods: We hypothesized that mesenchymal stromal cells (MSCs) would have beneficial effects in the treatment of H9N2 AIV-induced acute lung injury in mice. Six- to 8-week-old C57BL/6 mice were infected intranasally with $1 \times 10^{4} \mathrm{MID}_{50}$ of A/HONG KONG/2108/2003 [H9N2 (HK)] H9N2 virus to induce acute lung injury. After 30 min, syngeneic MSCs were delivered through the caudal vein. Three days after infection, we measured the survival rate, lung weight, arterial blood gas, and cytokines in both bronchoalveolar lavage fluid (BALF) and serum, and assessed pathological changes to the lungs.

Results: MSC administration significantly palliated H9N2 AIV-induced pulmonary inflammation by reducing chemokines and proinflammatory cytokines levels, as well as reducing inflammatory cell recruit into the lungs. Thus, H9N2 AIV-induced lung injury was markedly alleviated in mice treated with MSCs. Lung histopathology and arterial blood gas analysis were improved in mice with H9N2 AIV-induced lung injury following MSC treatment.
\end{abstract}

Conclusions: MSC treatment significantly reduces H9N2 AIV-induced acute lung injury in mice and is associated with reduced pulmonary inflammation. These results indicate a potential role for MSC therapy in the treatment of clinical avian influenza.

Keywords: Mesenchymal stromal cell, H9N2 avian influenza viruses, Lung injury, Cell therapy

Abbreviations: Al, Avian influenza; AIV, Avian influenza virus; ALI, Acute lung injury; ARDS, Acute respiratory distress syndrome; MSC, Mesenchymal stromal cell

\section{Background}

Infections with avian influenza virus (AIV) strains have become highly prevalent in poultry worldwide [1-4]. Avian influenza (AI) is a leading cause of morbidity, mortality, and economic loss in many countries. Mammals can also be infected with several AIV subtypes, including

\footnotetext{
*Correspondence: luwei@jscdc.cn; hanxd@nju.edu.cn

${ }^{\dagger}$ Equal contributors

'Department of Chronic Communicable Disease, Jiangsu Provincial Center for Disease Prevention and Control, Nanjing 210009, People's Republic of China

${ }^{2}$ Medical School, Nanjing University, Nanjing, Jiangsu 210093, People's

Republic of China

Full list of author information is available at the end of the article
}

H5N1, H9N2, H7N7, and H7N3 [5, 6]. In 1997, 18 people were infected with avian $\mathrm{H} 5 \mathrm{~N} 1$ influenza virus and six died, refocusing global attention on the potential role of AIVs as precursors of human pandemic influenza virus strains $[7,8]$. The H9N2 strain has been isolated from pigs and humans with influenza-like illnesses in Hong Kong and mainland China since 1998 [9, 10]. These findings indicate that the AIV can also cross species barriers and expand its host range from birds to mammals, thus highlighting the pandemic potential of the H9N2 virus.

Although the H9N2 avian virus subtype is generally not highly pathogenic for avian species, it has been associated with severe morbidity and mortality in poultry 
following coinfection with other pathogens [11, 12]. Recent findings indicate that the $\mathrm{H} 5 \mathrm{~N} 1$ viruses responsible for severe human disease contain genetic rearrangements that include several genes from obtained avian H9N2 viruses [13].

However, despite decades of research, few therapeutic strategies for clinical AI have emerged, and current specific treatment options are limited. Treatment of AI currently still relies on antiviral agents. A recent Cochrane review reported that antiviral therapies had little benefit for severe influenza patients $[14,15]$. Furthermore, AI continues to require prolonged mechanical ventilation in the intensive care unit, and $\mathrm{AI}$-associated mortality remains high at $30-50 \%$ despite optimal supportive care $[3,16]$.

The reasons for the high mortality associated with AI are unknown; the presence of a new viral subtype to which the human host has no prior immunity cannot totally explain this phenomenon. AIV is well known to mainly cause pneumonia, severe acute lung injury (ALI), and acute respiratory distress syndrome (ARDS) in humans [17]. A clinically important pronounced activation of the proinflammatory cytokine cascade perpetuates the inflammatory response and may contribute to further tissue damage and persistence of the systemic inflammatory response syndrome, leading to pulmonary infection in both animals and humans $[18,19]$. We therefore hypothesized that improving immune regulation would benefit the treatment of AI.

Cell therapies using bone marrow-derived mesenchymal stromal cells (MSCs) have emerged as potential novel therapeutic approaches for several diseases $[20,21]$. Several studies have shown that both ectogenic and endogenic MSCs can migrate into the lung, adopt the phenotype of lung cells, and play positive roles in repairing lung injury, including that caused by ARDS, emphysema, and idiopathic pulmonary fibrosis [22-24]. Importantly, recent studies have demonstrated that bone marrow-derived MSCs can exhibit immunosuppressive properties. In addition, MSCs have been suggested to be "immune evasive", and thus protected from rejection, which potentially permits their use in allotransplantation [25, 26]. MSCs may also engraft in the injured lung and can even differentiate into lung epithelial cells in vivo [27]. Therefore, MSCs may be beneficial in the treatment of AI.

The aim of this study was to evaluate the effect of MSC treatment on lung inflammation and injury induced by H9N2 AIV infection in a murine model.

\section{Methods}

Isolation, culture, and characterization of MSCs

MSCs were isolated from the bone marrow of C57BL/6 mice weighing 20-30 g, obtained from the Shanghai Laboratory Animal Research Center (Shanghai, China) and maintained under specific pathogen-free conditions. Bone marrow was flushed from the femurs under aseptic conditions using DMEM. The collected cells were washed three times with PBS, resuspended in DMEM containing $10 \%$ fetal bovine serum and $1 \%$ L-glutamine, and seeded at $1 \times 10^{6}$ cells $/ \mathrm{ml}$ into culture flasks. Cells were maintained in a humidified atmosphere of $95 \%$ air and $5 \% \mathrm{CO}_{2}$ at $37^{\circ} \mathrm{C}$. Nonadherent cells were discarded after $48 \mathrm{~h}$ and the culture medium changed every 3-4 days thereafter. Cells were harvested when they reached approximately $90 \%$ confluency and were diluted $1: 2$ or $1: 3$ at each passage. MSCs used in all in vivo experiments were between passages 3 and 10 .

\section{Fluorescence-activated cell sorting analysis}

Passage 3-10 MSCs were analyzed for the following markers: CD34, CD45, CD73, CD79, CD90, and CD105. A total of $1 \times 10^{5}$ cells were incubated with each fluorescence-conjugated primary antibody at $37^{\circ} \mathrm{C}$ for 2 $h$ in the dark. After three PBS washes, cells were processed by flow cytometry (BD FACSCalibur) and data were analyzed using Cell Quest software. Antibodies used were: anti-mouse CD34, CD45, and CD79 (Santa Cruz Biotechnology Inc.); anti-mouse CD73, CD90, and CD105 (BioLegend, San Diego, CA), and all of the antibodies were labeled with FITC.

\section{Differentiation of MSCs}

Passage 5 MSCs were differentiated into adipocytes, chondrocytes, and osteocytes using the Mouse Mesenchymal Stem Cell Functional Identification Kit (R\&D, USA) to prove their ability to differentiate into multiple mesenchymal lineages. Methods were according to the procedures of protocol; briefly, MSCs were plated at $1 \times 10^{4} /$ well in 24-well plates and incubated in $\alpha$-MEM containing $10 \%$ fetal bovine serum and $1 \% \mathrm{~L}$-glutamine until they reached approximately 50-70\% confluency for differentiation. Cells were cultured in adipogenic, osteogenic, or chondrogenic media for 10-21 days before being prepared for lineage-specific immunocytochemistry stains. Adipocytic differentiation was confirmed by staining with FABP4, differentiation to osteocytes was confirmed by staining with osteopontin, and differentiation to chondrocytes was confirmed by staining with collagen II as previously described. Briefly, cells were washed with PBS and fixed in $4 \%$ paraformaldehyde in PBS for $20 \mathrm{~min}$. The cells were permeabilized and blocked with $0.5 \mathrm{ml}$ PBS containing $0.3 \%$ Triton X-100 and $1 \%$ BSA at room temperature for 30 min. After blocking, the cells were incubated with Goat Anti-mouse FABP4, osteopontin, or Sheep Anti-mouse Collagen II antibody working solution for $1 \mathrm{~h}$ at $37^{\circ} \mathrm{C}$; they were then washed and incubated with Alexa 555 labelled Rabbit Anti-Goat secondary antibody in the dark for $60 \mathrm{~min}$ at room temperature. Images of the stained 
cells were obtained by using a phase fluorescence microscope (Axio Observer, Zeiss, Germany).

\section{Murine H9N2 infected mice of H9N2 AIV-induced acute lung injury}

A/Hong Kong/2108/2003 [H9N2 (HK)] AIV was kindly provided by Prof. Zheng Xing (Medicine School, Nanjing University). To assess pathological changes induced by H9N2 AIV, 6-week-old female SPF C57BL/6 mice were housed in microisolator cages in the animal facility of the Jiangsu Provincial Center for Disease Prevention and Control under conditions of negative pressure and ventilated with HEPA-filtered air.

A total of 95 C57BL/6 mice were divided into seven groups: A: controls $(n=10)$; B: MSCs $(n=10)$; C: H9N2 infected mice + physiological saline $(n=15) ;$ D: H9N2 infected mice + McCoy $(n=15)$; E: H9N2 infected mice + MSCs $(n=15) ;$ F: H9N2 infected mice + physiological saline $(n=15)$; G: H9N2 infected mice + MSCs $(n=15)$. Groups B-D had MSCs, McCoy, or saline administered $30 \mathrm{~min}$ following viral infection induction, while groups $\mathrm{E}$ and $\mathrm{F}$ were administered 1 day after. To induce lung injury in H9N2-infected mice, diethyl ether was used to anesthetize the mice and $1 \times 10^{4} \mathrm{MID}_{50}$ (Median Infective Dose) of A/ HONG KONG/2108/2003 [H9N2 (HK)] H9N2 AIV dissolved in $10 \mu \mathrm{l}$ sterile physiological saline was administered intranasally. Control mice were treated with noninfectious allantoic fluid of the equivalent dilution. Thirty minutes after H9N2 AIV challenge, physiological saline, McCoy, or syngeneic MSCs $\left(1 \times 10^{5}\right.$ cells; $100 \mu$ total volume $)$ were slowly infused into each mouse via the caudal vein. Naive mice (without H9N2 AIV instillation) were injected with saline or MSCs to serve as controls for any inflammatory response that might result from the injected MSCs. Mice were humanely killed by ether anesthesia followed by percutaneous left ventricular bleeding 3 days after MSC treatment and their tissues were harvested for analysis. McCoy was used as a negative control.

\section{Virus titration in lung of mice}

Virus titration in lung homogenate of three mice per group was detected to quantify the infection level. Tissues were collected and homogenized in cold phosphatebuffered saline on day 3 after treatment. Clarified homogenates were titrated for viral infectivity in embryonated chicken eggs from initial dilutions of 1:2. Viral titers were expressed as mean $\log 10 \mathrm{EID}_{50} / \mathrm{ml} \pm \mathrm{SD}\left(1 \mathrm{MID}_{50}\right.$ is around $1 \times 10^{3} \mathrm{EID}_{50}$ ).

\section{Survival rate and lung weight}

Three days after treatment, the survival rate was observed for each experimental group. In addition, the upper right lung lobes were weighed before and after oven desiccation at $70{ }^{\circ} \mathrm{C}$ to determine the lung wet:dry weight ratio. Lung wet:dry weight ratio = weight of the wet lung/weight of the dry lung; relative lung weight $(\%)=$ weight of the whole wet lung/body weight $\times 100 \%$. These were used as indicators of lung edema.

\section{Histopathology}

Lung tissue samples of three mice per group (one cross section of the right lower lobe, one of the right mid lobe, and one of the right upper lobe) were fixed in $4 \%$ paraformaldehyde, embedded in paraffin, and cut into $4-\mu \mathrm{m}$ thick sections. Sections were stained with hematoxylin and eosin, and observed using an optical microscope. All lungs were uniformally inflated and fixed in the same way. The average interalveolar septum thickness was quantified in a blinded fashion by measuring the thickness of all septae along a crosshair placed on each image (at least 100 septae were measured per animal). Lung injury score was observed for quantification of the lung damage; briefly, images were evaluated by an investigator who was blinded to the identity of the slides (WCL) according to a previously defined scoring system [28]. The grading system was as follows: 0 , minimal damage; 1 , mild damage; 2 , moderate damage; 3 , severe damage; and 4 , maximal damage.

\section{Arterial blood gas analysis}

Five mice from each group were anesthetized with diethyl ether on day 3 postinoculation. Arterial blood samples $(100 \mu \mathrm{l})$ of lightly anesthetized mice spontaneously breathing room air were withdrawn into a heparinized syringe by percutaneous left ventricular sampling. Blood gas analysis was immediately performed with an i-STAT 300 blood gas/electrolytes analyzer (Abbott, USA).

\section{Cytokine measurement}

Concentrations of the chemokines granulocyte-macrophage colony-stimulating factor (GM-CSF), monocyte chemoattractant protein (MCP-1), keratinocyte chemoattractant $(\mathrm{KC})$, macrophage inflammatory protein $-1 \alpha(\mathrm{MIP}-1 \alpha)$, and monokine induced by IFN- $\gamma$ (MIG) and the inflammatory cytokines interleukin (IL)- $1 \alpha$, IL-6, IL-10, tumor necrosis factor alpha (TNF- $\alpha$ ), and interferon (IFN- $\gamma$ ) in bronchoalveolar lavage fluid (BALF) and serum (five mice from each group) were measured 3 days after H9N2 infection using the Mouse Cytokine Magnetic 20-Plex Panel (Invitrogen) by Luminex 100 (Bio-Rad, USA).

BALF of mice was collected immediately following sacrifice. Briefly, the lungs were lavaged three times with a total volume of $1.0 \mathrm{ml}$ physiological saline $\left(4{ }^{\circ} \mathrm{C}\right)$ in the chest cavity opened by midline incision. The rate of recovery of BALF was not less than $90 \%$ for all of the animals tested. 


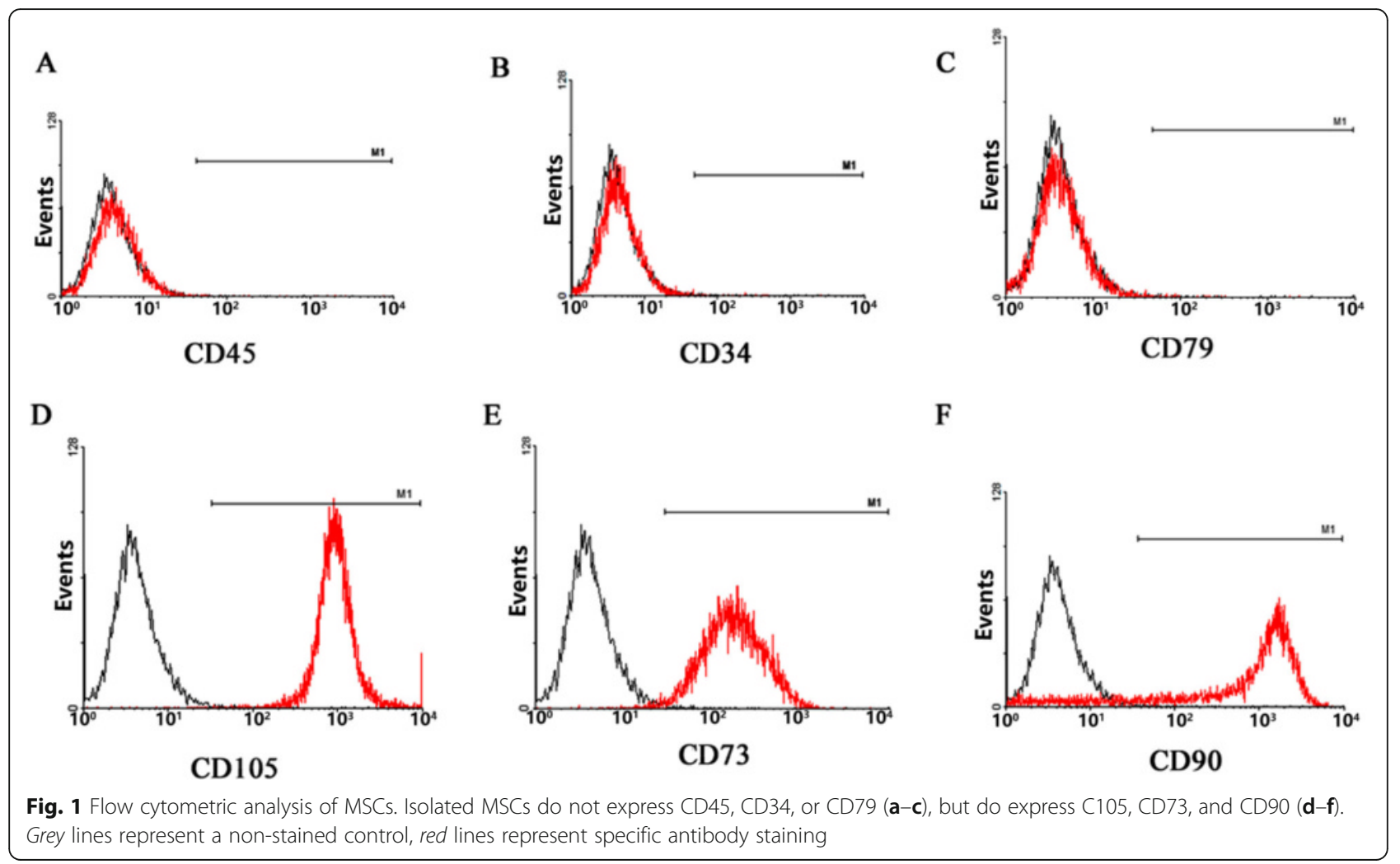

\section{Protein expression}

Expression of CD14, TLR4, ERK, and JNK protein in lung tissue was measured 3 days after H9N2 infection using Western blotting. Lung tissue proteins were obtained from the right lower lungs of mice in each group. Briefly, tissues were lysed in ice-cold extraction buffer containing protease inhibitor cocktail (Roche) and then centrifuged at $12,000 \mathrm{~g}$ for $30 \mathrm{~min}$; the protein concentration in the supernatant was determined using BCA assays. Proteins were separated using $10 \%$ SDS-polyacrylamide gel electrophoresis and electrophoretically transferred to polyvinylidene fluoride (PVDF) membranes using

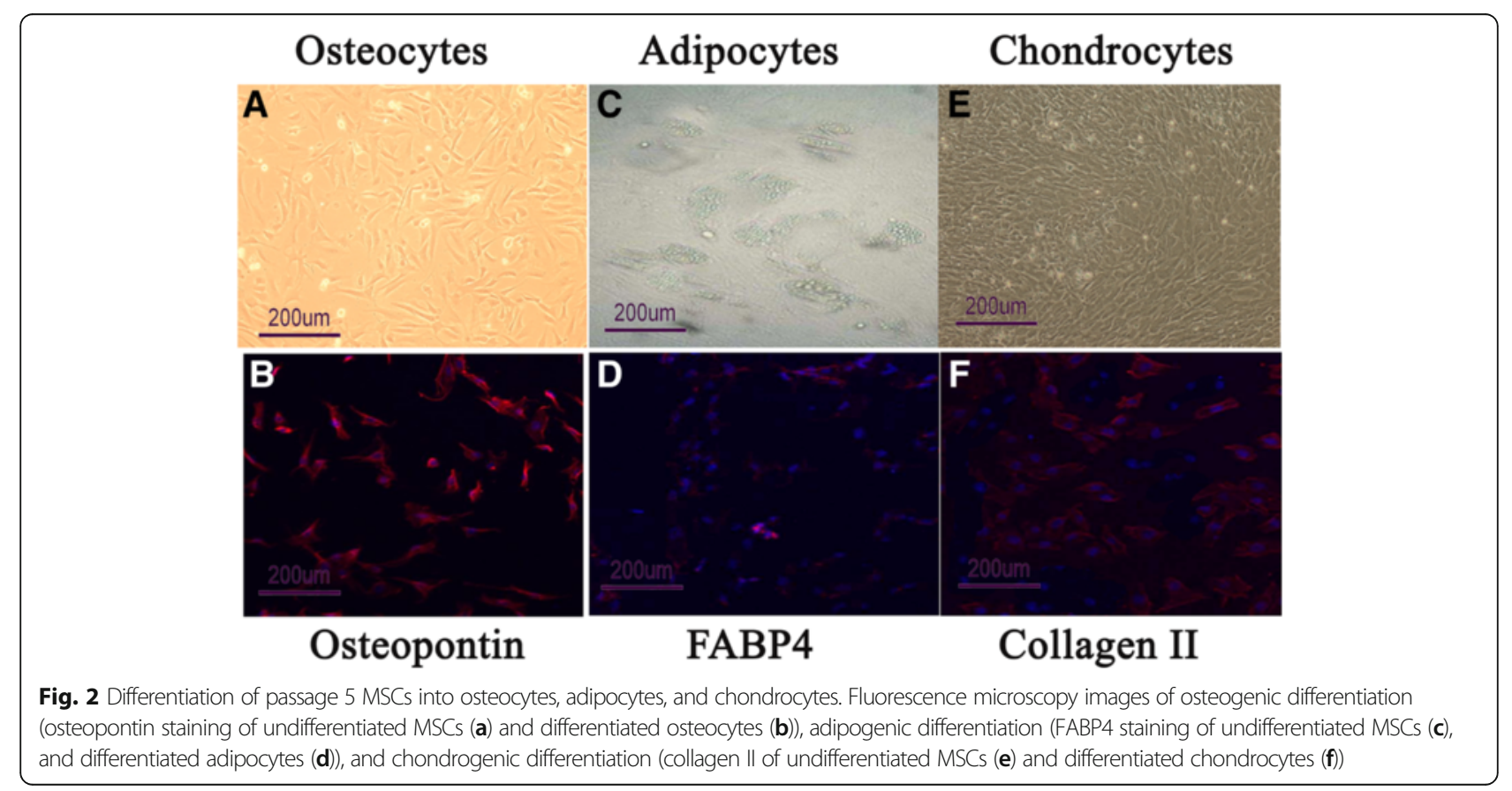




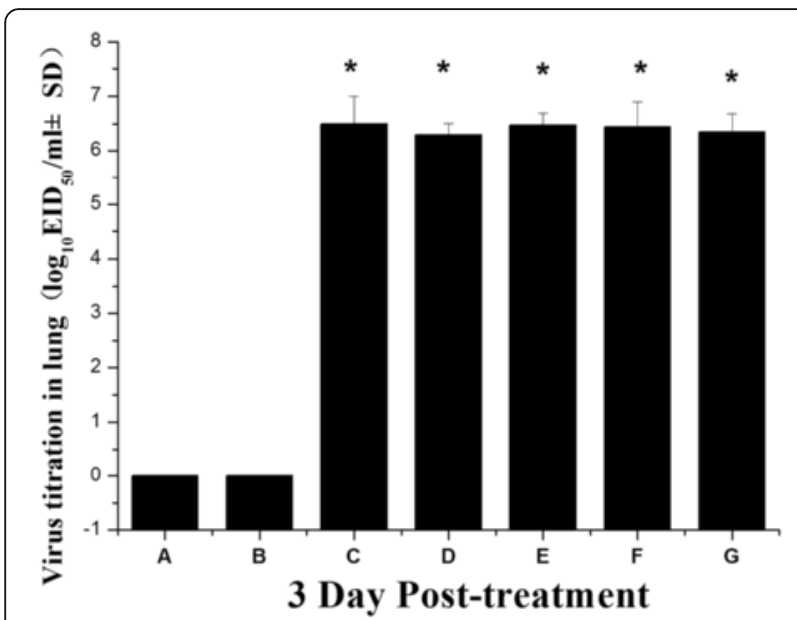

Fig. 3 Virus titration in the lungs of mice. Mean viral titers based on three mice per group are expressed as $\log _{10}$ EID $_{50}$ per milliliter $\pm S D$

standard procedures. The membranes were blocked at $37{ }^{\circ} \mathrm{C}$ for $1 \mathrm{~h}$ in phosphate-buffered saline (PBS) containing $0.05 \%$ (vol/vol) Tween 20 and $5 \%$ (wt/vol) non-fat milk for $1 \mathrm{~h}$ at RT. Membranes were then incubated in primary antibody at a 1:500 dilution in PBSTM (PBS containing $0.05 \%$ ( $\mathrm{vol} / \mathrm{vol}$ ) Tween 20 and $0.1 \%$ (wt/vol) non-fat milk) for $3 \mathrm{~h}$ at $\mathrm{RT}$ and then washed three times for 5 min each in PBSTM. Membranes were then incubated with the appropriate horseradish peroxidase (HRP)-conjugated anti-species secondary antibodies (Boster, Wuhan, China) for $1 \mathrm{~h}$ at RT and then washed in PBSTM as described above. Immunoreactive protein bands were detected using an Odyssey Scanning System (LI-COR, Inc., Lincoln, NE, USA). Ratios for the protein of interest (POI) were expressed relative to GAPDH in the same sample as a loading control. The primary antibodies rabbit antiCD14, TLR4, ERK, JNK, and GAPDH were obtained from Santa Cruz (USA).

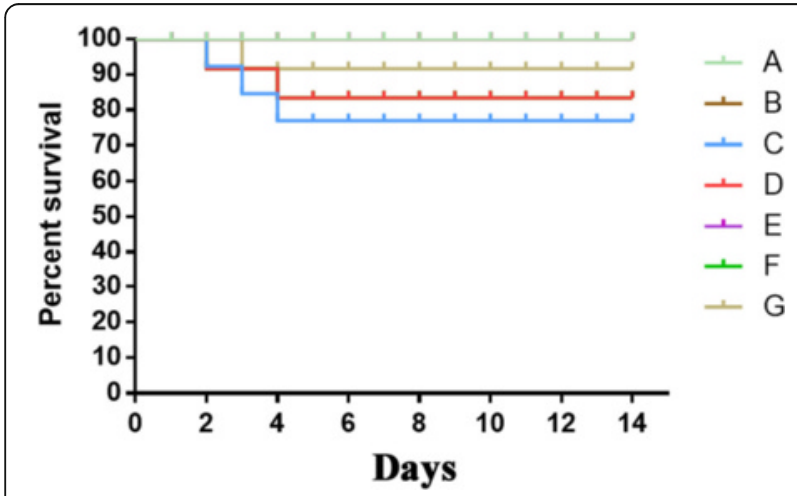

Fig. 4 The survival rate of mice in different experimental groups 3 days post-treatment. Kaplan-Meier curves are shown for mice in different groups. MSCs could improve survival in experimental Al mice. See text for definition of groups A-G

\section{Ethics Statement}

This study was carried out in strict accordance with the recommendations in the Guide for the Care and Use of Laboratory Animals of the National Institutes of Health. The protocol was approved by the Committee on the Ethics of Animal Experiments of the University of Minnesota (approval no. A9089). All surgery was performed under sodium pentobarbital anesthesia, and all efforts were made to minimize suffering.

\section{Statistical analysis}

Data are expressed as the mean \pm standard deviation (S.D.). All calculations and statistical analyses were performed using SPSS for windows version 13.0 (SPSS Inc., Chicago, IL, USA). One-way ANOVA followed by Dunnett's $t$ test was used to analyze differences between groups. $P<0.05$ was regarded as statistically significant.

\section{Results}

Highly pure MSCs can be isolated from murine bone marrow

After approximately 2 weeks of culture, isolated MSCs had expanded significantly and exhibited evident plastic adherence. After three to four passages, MSCs exhibited a homogeneous fibroblast-like, spindle-shaped morphology. FACS analysis demonstrated that passage 3-10 MSCs did not express CD34, CD45, or CD79 (Fig. 1a-c), but did express CD73, CD90, and CD105 (Fig. 1d-f). These data indicate that the cultured cells were of mesenchymal origin and of a high purity. Passage 5 MSCs readily differentiated into adipocytes, osteocytes, or chondrocytes when incubated in differentiation medium, confirming their pluripotent potential (Fig. 2).

\section{Virus titration in the lungs of mice}

H9N2 viral infection resulted in high viral titers in the lungs; the viral titers of the H9N2 infected mice + physiological saline group, H9N2 infected mice + McCoy group, and H9N2 infected mice + MSCs group exceeded $6.0 \log _{10} \mathrm{EID}_{50} / \mathrm{ml}$ (Fig. 3) on day 3 post-infection.

\section{Survival rate and lung weight}

Three days after infusion of MSCs, we observed that the survival rate of mice in the H9N2 infected mice + MSCs group was higher than that of the H9N2-infected mice groups; the survival rate of the H9N2 infected mice + MSCs group was $100 \%$, whereas that of the H9N2infected mice groups were approximately $80 \%$ (3 deaths out of 15 mice in the H9N2 infected mice + physiological saline group and 2 deaths out of 15 mice in the H9N2 infected mice + McCoy groups) (Fig. 4).

Mean relative lung weights and lung wet:dry weight ratios were significantly higher $(p<0.05)$ in H9N2infected lungs versus control mice and significantly 


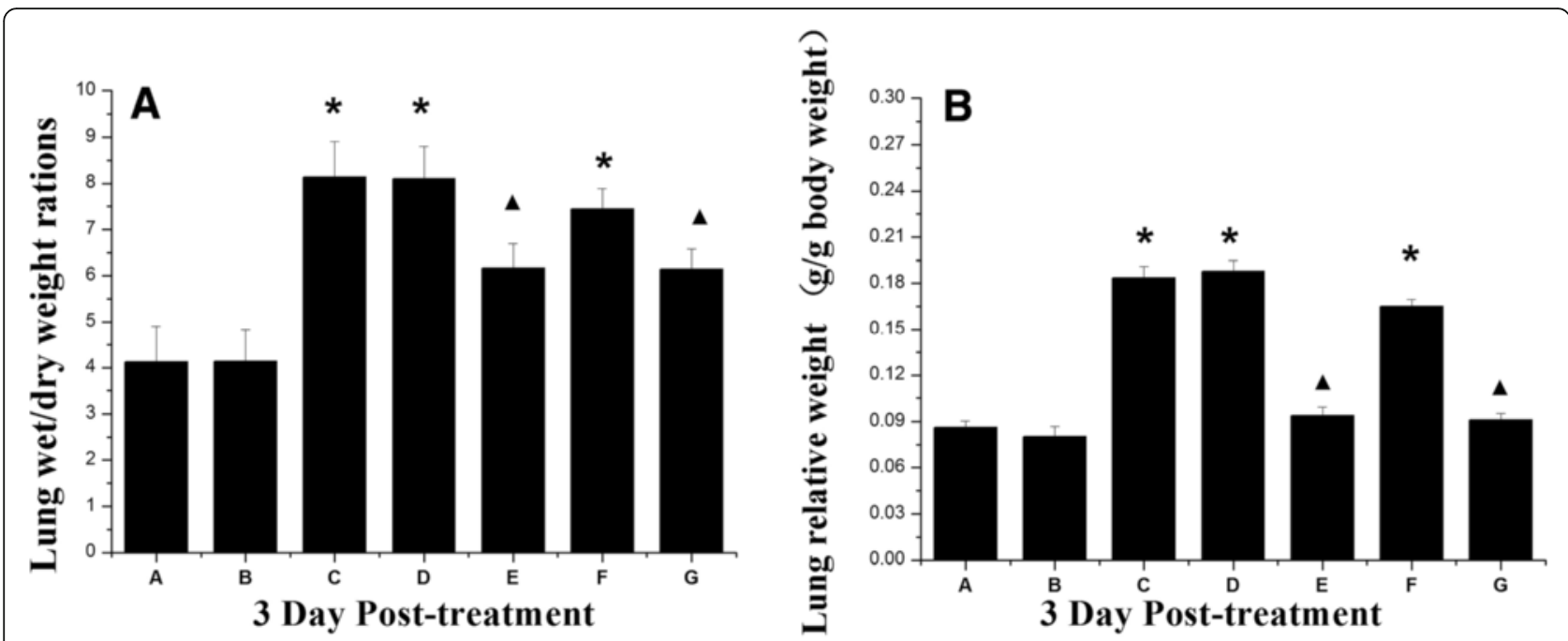

Fig. 5 Effect of MSCs on lung weights of mice in comparison to control mice. a Lung wet:dry weight ratios and $\mathbf{b}$ relative lung weight. * Response that is significantly different from the control $(p<0.05)$. Response that is significantly different from the H9N2 infected mice $(p<0.05)$. See text for definition of groups $A-G$

lower $(p<0.05)$ in mice treated with H9N2 + MSCs versus those of the H9N2-infected groups (Fig. 5).

\section{Histopathology}

Lung sections from mice in the H9N2 infected mice + physiological saline group and H9N2 infected mice + McCoy group displayed similar histopathological patterns consistent with severe diffuse pneumonia and characterized by inflammatory cellular infiltration, numerous polymorphonuclear leukocytes and macrophages in interstitial spaces, interstitial and alveolar edema, and hemorrhage. Diffuse pneumonia with severe alveolar damage was observed throughout the entire lung (Fig. 6c and d). Administration of MSCs (H9N2 infected mice + MSCs) reduced airspace inflammation and improved lung histopathology.
Lung structure was less abnormal than in the H9N2 infected mice + physiological saline group, suggesting that therapy with MSCs is protective against H9N2-induced lung injury (Fig. 6e). The severity of lung injury was also assessed using a semiquantitative histopathological scoring system that evaluated lung injury in four categories: alveolar septae, alveolar hemorrhage, intra-alveolar fibrin, and intraalveolar infiltrates. Although treatment with MSCs tended to reduce lung injury scores (Fig. 7), the observed differences did not reach statistical significance.

\section{Arterial blood gas analysis}

Arterial blood gas parameters in the different experimental groups are shown in Table 1. In the H9N2infected mice, the partial pressure of arterial oxygen
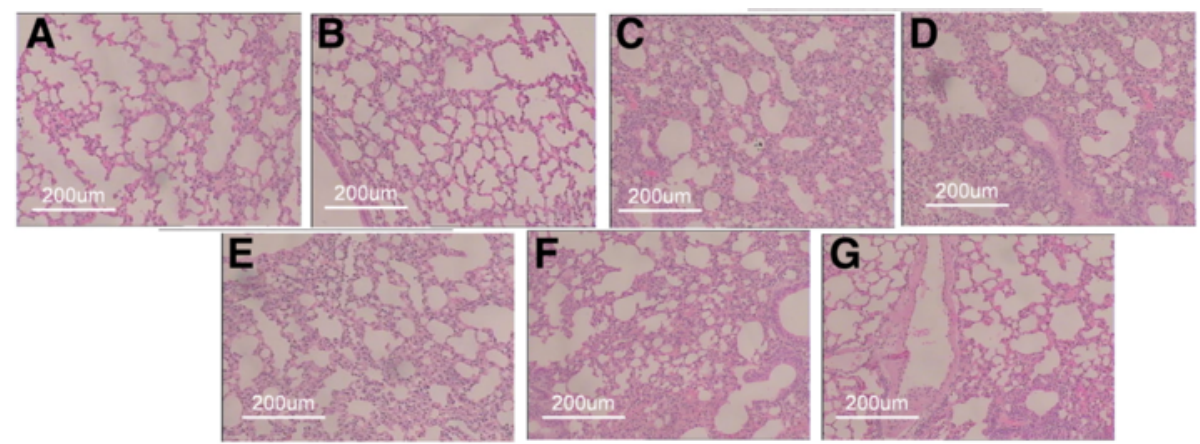

Fig. 6 Histological evaluation of the therapeutic potential of MSCs on AIV-induced lung injury in mice. Lung pathology of mice in different experimental groups 3 days post-treatment (hematoxylin and eosin, 100× magnification). a Control group, b MSC group (lungs of control and MSC groups showed a

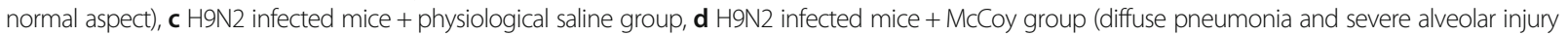
were observed), e H9N2 infected mice + MSCs group (MSC transplantation reduced lung injury). $\mathbf{f}$ H9N2 infected mice+ Physiological saline administer 1 day following viral infection induction (Severe diffuse pneumonia and extensive alveolar damage). $\mathbf{g}$ H9N2 infected mice+MSCs administer 1 day following viral infection induction (MSC transplantation reduced lung inflammation and injury) 


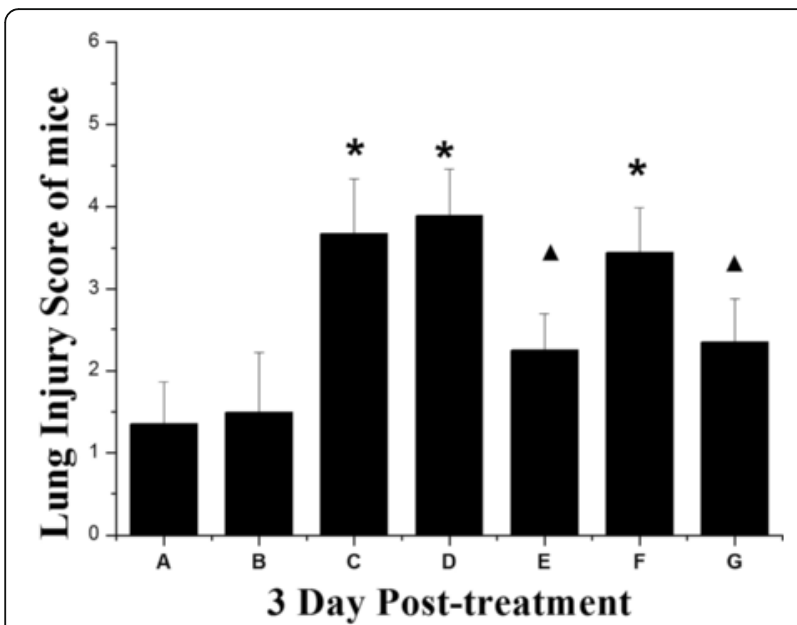

Fig. 7 Lung injury score of mice in different experimental groups 3 days post-treatment. Data are represented as mean \pm standard error of the mean; $n=6$ per group. *Response that is significantly different from the control $(p<0.05)$. ${ }^{\boldsymbol{\Delta}}$ Response that is significantly different from the H9N2 infected mice $(p<0.05)$. See text for definition of groups $A-G$

$\left(\mathrm{PaO}_{2}\right)$ was significantly lower, while the partial pressure of arterial carbon dioxide $\left(\mathrm{PaCO}_{2}\right)$ was significantly higher, and the values for saturation of arterial oxygen $\left(\mathrm{SaO}_{2}\right)$ and $\mathrm{pH}$ were slightly lower. Compared with the H9N2 infected mice + physiological saline and H9N2 infected mice + McCoy groups, mice in the H9N2 infected + MSCs group had significantly higher $\mathrm{PaO}_{2}$, significantly lower $\mathrm{PaCO}_{2}$, and slightly higher (but still statistically significantly different) $\mathrm{SaO}_{2}$ and $\mathrm{pH}$ values. These results indicate that most of the $\mathrm{H} 9 \mathrm{~N} 2$ AIV infected mice developed severe hypoxemia, and that MSCs effectively protected against functional pulmonary injury.

\section{Cytokine measurements}

\section{Chemokines}

Three days after H9N2 infection, the concentrations of GM-CSF, MCP-1, KC, MIP-1 $\alpha$, and MIG were measured in both BALF and serum. The concentrations of all chemokines were increased in BALF and serum (Fig. 8) in the $\mathrm{H} 9 \mathrm{~N} 2$ infected mice + physiological saline group. In contrast, the concentrations of chemokines were much lower in the H9N2 infected mice + MSCs group.

\section{Inflammatory cytokines}

The concentrations of IL- $1 \alpha$, IL- 6 , IL-10, TNF- $\alpha$, and IFN- $\gamma$ were measured in BALF and serum 3 days after $\mathrm{H} 9 \mathrm{~N} 2$ infection. In the H9N2 infected mice + physiological saline group, the concentrations of these inflammatory cytokines were significantly increased in both BALF and serum (Fig. 9). In contrast, the concentrations were significantly lower in the H9N2 infected mice + MSCs group.

\section{Protein expression}

Three days after H9N2 infection, the expression of CD14, TLR4, ERK and JNK protein in the lung tissue was measured. In the H9N2-infected mice, the expression of CD14, TLR4, ERK, and JNK protein in lung tissue was significantly increased compared with the control group. Mice in the H9N2 infected + MSCs group had significantly decreased ERK and JNK expression compared with the H9N2 infected mice + physiological saline and H9N2 infected mice + McCoy groups. The expression of CD14 and TLR4 in mice in the H9N2 infected + MSCs group tended to be lower, although not significantly so (Fig. 10).

\section{Discussion}

The present study demonstrated that MSCs exert a beneficial therapeutic effect on H9N2 AIV-induced lung injury in a murine model; treatment with MSCs results in improvements in both pulmonary inflammation and lung tissue organization. These findings have potentially important implications for the treatment of AI, which is an important clinical problem characterized by high patient morbidity and mortality.

Table 1 Effect of H9N2 avian influenza virus (AIV) and mesenchymal stromal cells (MSCs) on arterial blood gas analysis of mice

\begin{tabular}{|c|c|c|c|c|}
\hline Groups & $\mathrm{pH}$ & $\mathrm{PO}_{2}(\mathrm{mmHg})$ & $\mathrm{PCO}_{2}(\mathrm{mmHg})$ & $\mathrm{SO}_{2}$ \\
\hline A: Control (allantoic fluid; $n=10$ ) & $7.23 \pm 0.032$ & $90.8 \pm 6.43$ & $38.5 \pm 1.66$ & $92.7 \pm 0.73$ \\
\hline B: MSCs $\left(1 \times 10^{5}\right.$ MSCs; $\left.n=10\right)$ & $7.29 \pm 0.031$ & $88.2 \pm 5.51$ & $37.9 \pm 1.11$ & $93.8 \pm 1.02$ \\
\hline C: H9N2-infected mice $\left(1 \times 10^{4}\right.$ MID $_{50}$ H9N2AIV; $\left.n=15\right)$ & $6.62 \pm 0.286$ & $46 \pm 4.17^{*}$ & $65.34 \pm 2.55^{*}$ & $64.82 \pm 1.63^{*}$ \\
\hline D: H9N2-infected mice + MSCs $\left(1 \times 10^{4}\right.$ MID $_{50}$ H9N2AIV $+1 \times 10^{5}$ McCoy; $\left.n=15\right)$ & $6.71 \pm 0.257$ & $48.2 \pm 5.11^{*}$ & $64.32 \pm 1.98^{*}$ & $68.15 \pm 1.75^{*}$ \\
\hline $\begin{array}{l}\text { E: H9N2-infected mice }+ \text { MSCs }\left(1 \times 10^{4} \text { MID }_{50} \text { H9N2AIV + } 1 \times 10^{5} \text { MSCs; }\right. \\
n=15,30 \text { min following infection })\end{array}$ & $6.84 \pm 0.613$ & $68 \pm 5.76^{* \boldsymbol{\Lambda}}$ & $50.05 \pm 1.09^{* \boldsymbol{\Lambda}}$ & $78.47 \pm 1.54^{*}$ \\
\hline F: H9N2-infected mice $\left(1 \times 10^{4}\right.$ MID $_{50}$ H9N2AIV; $\left.n=15\right)$ & $6.97 \pm 0.375$ & $46 \pm 4.35^{*}$ & $66 \pm 3.34^{*}$ & $65 \pm 2.44^{*}$ \\
\hline $\begin{array}{l}\text { G: H9N2-infected mice }+ \text { MSCs }\left(1 \times 10^{4} \text { MID50 H9N2AIV }+1 \times 10^{5} \text { MSCs; }\right. \\
n=15,1 \text { day following infection) }\end{array}$ & $6.77 \pm 0.712$ & $60 \pm 3.35^{* \boldsymbol{\Lambda}}$ & $52.39 \pm 4.13^{* \boldsymbol{\Lambda}}$ & $75.89 \pm 2.44^{* \boldsymbol{\Lambda}}$ \\
\hline
\end{tabular}

*Response that is significantly different from the control $(p<0.05)$

$\Delta$ Response that is significantly different from the H9N2-infected mice $(p<0.05)$

$\mathrm{PaCO}_{2}$ partial pressure of arterial carbon dioxide, $\mathrm{PaO}_{2}$ partial pressure of arterial oxygen, $\mathrm{SaO}_{2}$ saturation of arterial oxygen 

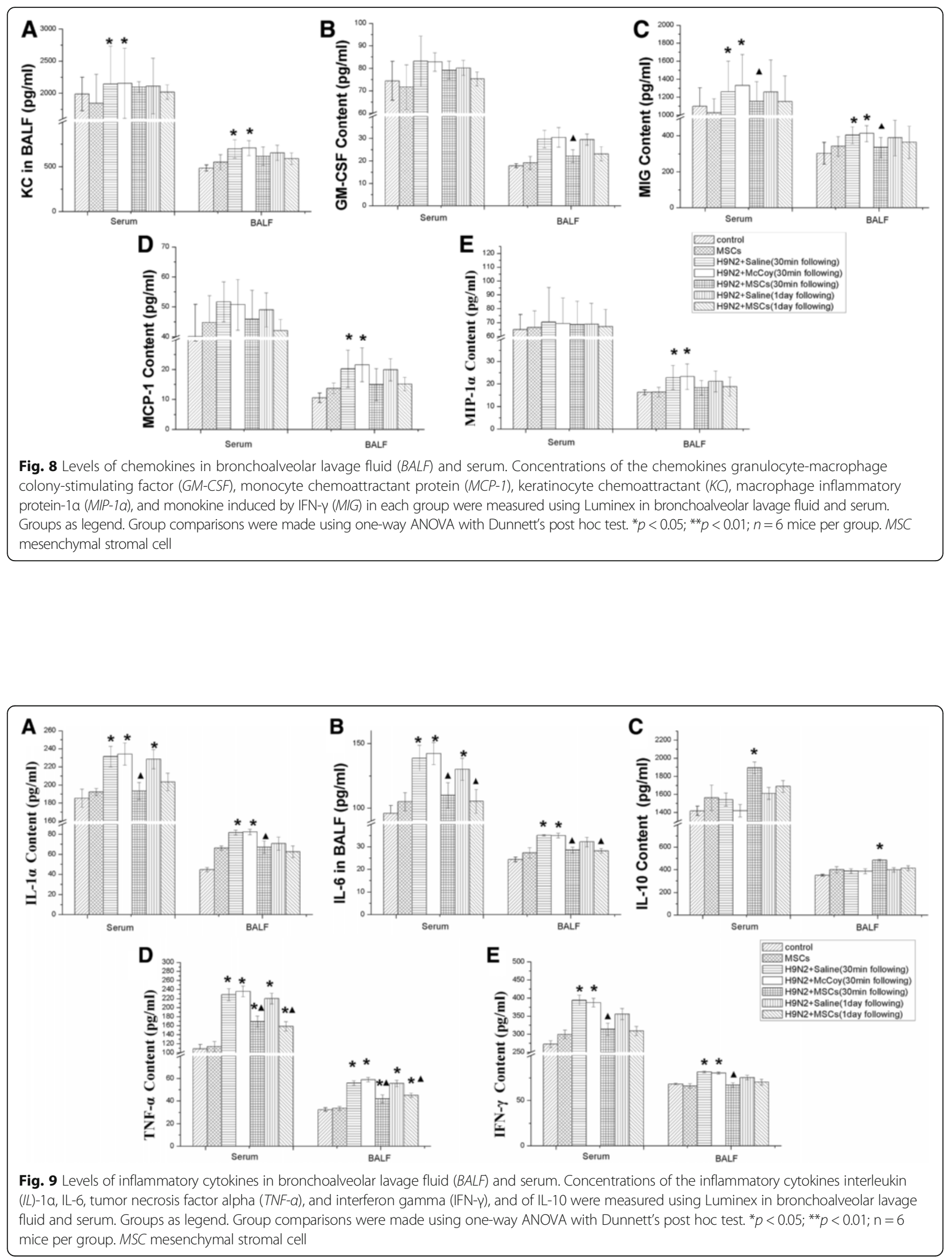


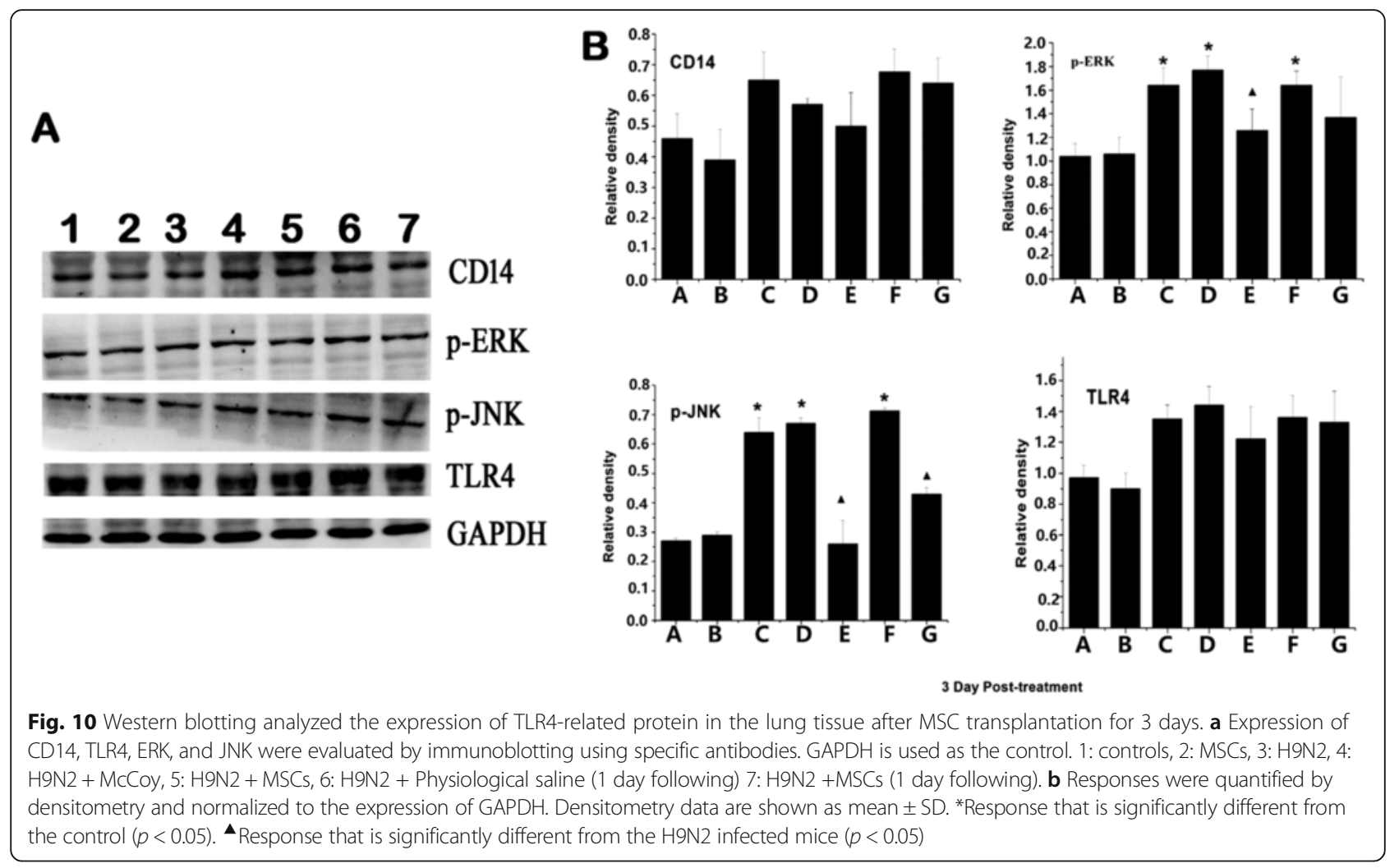

Avian H9N2 viruses have been widespread in domestic poultry in Asian countries since the mid-1990s, with a mortality ranging from 5-30\% [29, 30]. Many studies have shown that $\mathrm{H} 9 \mathrm{~N} 2$ viruses can cause upper respiratory tract illnesses in humans. This indicates that the virus has evolved to cross the species barrier and is capable of infecting humans, bypassing intermediate hosts.

H9N2 viruses can activate the innate immune response. A hallmark of pulmonary infiltration associated with AI is the presence of infiltrating leukocytes [31, 32]. Leukocyte migration is directed largely by chemokines, and the inter-relationship of early-response cytokines, adhesion molecules, and chemokines orchestrates the recruitment of neutrophils into the lungs [33]. In most studies, cytokines have been described as forming an inflammatory "cascade" or "network" in patients [30, 34]. Lung injury may be a direct consequence of this inflammatory response.

Adult stem cells or progenitor cells are being evaluated for the treatment of a number of diseases that currently have limited or no treatment options [35, 36]. Marrowderived stem cells are hypothesized to be the source of lung regeneration and repair. An alternative source are exogenous stem/progenitor cells, delivered into the lung either intravenously via the trachea or by direct injection. Recently, many studies have confirmed that MSCs can engraft in the injured lung [37-39] and can even differentiate into lung epithelial cells in vivo. MSCs may also exhibit immunosuppressive properties, suggesting "immune-privilege", and may even have certain immune regulation functions [40-42]. Therefore, MSCs may, in their own right, have beneficial effects in ALI.

Our data showed that H9N2 viral infection dramatically increases the expression of chemokines, including GMCSF, MCP-1, KC, MIP-1 $\alpha$, and MIG, in both BALF and serum. However, MSC treatment decreases the expression of these chemokines. We also showed that MSC-treated mice have significantly reduced levels of some inflammatory cytokines (IL- $1 \alpha$, IL- 6, TNF- $\alpha$, and IFN- $\gamma$ ) and a corresponding increase in anti-inflammatory cytokines (IL-10). It is believed that IL-1 $\alpha$, IL-6, TNF- $\alpha$, and IFN- $\gamma$ play important roles in the development of ALI [43]. These results are consistent with several previous studies. For example, in Mei's study, treatment with MSCs alone significantly reduced LPS-induced acute pulmonary inflammation in mice [39]. Importantly, our in vivo experimental results suggest that the administration of MSCs can greatly improve the hypoxemia and histopathological changes of lung injury induced by H9N2 AIV infection. The data indicate that administration of MSCs results in a marked increase in survival rates, primarily due to a decrease in ALI. These results are not consistent with the findings of Lam et al. [44], who reported that MSC therapy fails to improve outcomes in experimental HIN1 influenza. We speculate that this might be a consequence of 
different pathogenic characteristics of different influenza viruses. It is known that avian influenza virus infection can lead to a "cytokine storm". In consequence, the host cellular response may be different from that with H1N1 influenza virus infection.

We have, therefore, demonstrated that MSC-based cell therapy can attenuate the inflammatory reaction and injury in the lungs caused by H9N2 AIV exposure, as well as by reducing lung histopathological changes. These beneficial effects may be mediated by the downregulation of chemokines such as GM-CSF, MCP-1, KC, MIP$1 \alpha$, and MIG, leading to the downregulation of inflammatory cytokines such as TNF- $\alpha$, IL-1 $\alpha$, IL- 6 , and IFN- $\gamma$. Our findings provide further support for a prominent role of TLR4-dependent immune regulation in acute lung injury therapy. The quantity of stem cells used in our study was $1 \times 10^{5}$. This is much less than used by Wang et al. [45]. We did not find an obvious stem cell niche in the lung tissue of mice. Therefore, we deduce that the immune regulation function of stem cells is via a paracrine mechanism.

On the other hand, it is possible that MSCs may be involved in the early stages of carcinogenesis through spontaneous transformation. In addition, it has been suggested that MSCs can modulate tumor growth and metastasis, although this remains controversial and poorly understood. Interestingly, different studies have reported contradicting findings, with some finding that MSCs promote tumor growth and others that they inhibit tumor growth. Therefore, the role of MSCs in avian influenza infection requires ongoing surveillance.

\section{Conclusions}

Our results suggest that MSC-based therapy can reduce inflammatory lung injury and pulmonary vascular permeability. This may provide a novel strategy for the treatment of AIV-induced lung injury through improving tissue repair and protecting against inflammation. Further investigations into the application of MSC-based cell therapy may give new hope for patients with AIV-induced ALI.

\section{Acknowledgments}

The authors thank Dr. Zheng Xing for his kind help. They also thank Xueting Wang, Yu Chen, Xuemin Gong, and Yuan Zhou for their technical assistance, and Dr. Leonardo Martinez for his editorial assistance.

\section{Funding}

This work was supported by National Natural Science Foundation of China (81170054;81301448), Natural Science Foundation of Jiangsu Province of China (BK2011570,), the National Basic Research Program of China (973 program 2010CB945103), and Open Research Fund of State Key Laboratory of Bioelectronics, Southeast University, Key Medical Talent Foundation of Jiangsu Provincial Center for Disease Prevention and Control (JKRC20110029).

\section{Authors' contributions}

$Y L$ and JX performed and analyzed the majority of the experiments and wrote the manuscript. YL, XH, and WL were responsible for obtaining funds and designed the whole study concept, and drafted and revised the manuscript.
WS and JX performed animal experiments, conducted the experimental analysis and drafted and revised the manuscript. CC and YS performed the cells experiments, conducted the experimental analysis and drafted and revised the manuscript. LZ participated in the writing and revision of the manuscript. All authors read and approved the final manuscript.

\section{Competing interests}

The authors declare that they have no competing interests.

\section{Ethics approval and consent to participate}

This study was carried out in strict accordance with the recommendations in the Guide for the Care and Use of Laboratory Animals of the National Institutes of Health. The protocol was approved by the Committee on the Ethics of Animal Experiments of the University of Minnesota (approval no. A9089). All surgery was performed under sodium pentobarbital anesthesia, and all efforts were made to minimize suffering.

\section{Author details}

${ }^{1}$ Department of Chronic Communicable Disease, Jiangsu Provincial Center for Disease Prevention and Control, Nanjing 210009, People's Republic of China. ${ }^{2}$ Medical School, Nanjing University, Nanjing, Jiangsu 210093, People's Republic of China. ${ }^{3}$ Institute of Toxicology \& Functional Assessment, Jiangsu Provincial Center for Disease Prevention and Control, Nanjing 210009, People's Republic of China.

Received: 6 June 2016 Revised: 3 August 2016 Accepted: 24 August 2016 Published online: 28 October 2016

\section{References}

1. Si Y, de Boer WF, Gong P. Different environmental drivers of highly pathogenic avian influenza H5N1 outbreaks in poultry and wild birds. PLoS One. 2013;8:e53362.

2. Qi X, Cui L, Jiao Y, Pan Y, Li X, Zu R, Huo X, Wu B, Tang F, Song Y, Zhou M, Wang $\mathrm{H}$, Cardona $\mathrm{CJ}$, Xing Z. Antigenic and genetic characterization of a European avian-like H1N1 swine influenza virus from a boy in China in 2011. Arch Virol. 2013;158:39-53.

3. Metras R, Stevens KB, Abdu P, Okike I, Randolph T, Grace D, Pfeiffer DU, Costard S. Identification of potential risk factors associated with highly pathogenic avian influenza subtype H5N1 outbreak occurrence in Lagos and Kano States, Nigeria, during the 2006-2007 epidemics. Transbound Emerg Dis. 2013;60:87-96.

4. Parker CD, Reid SM, Ball A, Cox WJ, Essen SC, Hanna A, Mahmood S, Slomka MJ, Irvine RM, Brown $I H$. First reported detection of a low pathogenicity avian influenza virus subtype $\mathrm{H} 9$ infection in domestic fowl in England. Vet Rec. 2012;171:372

5. Younan M, Poh MK, Elassal E, Davis T, Rivailler P, Balish AL, Simpson N, Jones J, Deyde V, Loughlin R, Perry I, Gubareva L, ElBadry MA, Truelove S, Gaynor AM, Mohareb E, Amin M, Cornelius C, Pimentel G, Earhart K, Naguib A, Abdelghani AS, Refaey S, Klimov Al, Donis RO, Kandeel A. Microevolution of highly pathogenic avian influenza $\mathrm{A}(\mathrm{H} 5 \mathrm{~N} 1)$ viruses isolated from humans, Egypt, 2007-2011. Emerg Infect Dis. 2013;19:43-50.

6. Su S, Qi W, Chen J, Zhu W, Huang Z, Xie J, Zhang G. Seroepidemiological evidence of avian influenza A virus transmission to pigs in southern China. J Clin Microbiol. 2013;51:601-2.

7. Kandun IN, Tresnaningsih E, Purba WH, Lee V, Samaan G, Harun S, Soni E, Septiawati C, Setiawati T, Sariwati E, Wandra T. Factors associated with case fatality of human $\mathrm{H} 5 \mathrm{~N} 1$ virus infections in Indonesia: a case series. Lancet. 2008;372:744-9.

8. Tam JS. Influenza A, (H5N1) in Hong Kong: an overview. Vaccine. 2002;20 Suppl 2:S77-81.

9. Peiris M, Yuen KY, Leung CW, Chan KH, Ip PL, Lai RW, Orr WK, Shortridge KF. Human infection with influenza H9N2. Lancet. 1999;354:916-7.

10. Butt KM, Smith GJ, Chen H, Zhang LJ, Leung YH, Xu KM, Lim W, Webster RG, Yuen KY, Peiris JS, Guan Y. Human infection with an avian H9N2 influenza A virus in Hong Kong in 2003. J Clin Microbiol. 2005;43:5760-7.

11. Tombari W, Paul M, Bettaieb J, Larbi I, Nsiri J, Elbehi I, Gribaa L, Ghram A. Risk factors and characteristics of low pathogenic avian influenza virus isolated from commercial poultry in Tunisia. PLoS One. 2013;8:e53524.

12. Kim HR, Lee KK, Kwon YK, Kang MS, Moon OK, Park CK. Comparison of serum treatments to remove nonspecific inhibitors from chicken sera for 
the hemagglutination inhibition test with inactivated H5N1 and H9N2 avian influenza A virus subtypes. J Vet Diagn Invest. 2012;24:954-8.

13. Lin YP, Shaw M, Gregory V, Cameron K, Lim W, Klimov A, Subbarao K, Guan Y, Krauss S, Shortridge K, Webster R, Cox N, Hay A. Avian-to-human transmission of H9N2 subtype influenza A viruses: relationship between H9N2 and H5N1 human isolates. Proc Natl Acad Sci U S A. 2000;97:9654-8.

14. Ortiz JR, Rudd KE, Clark DV, Jacob ST, West TE. Clinical research during a public health emergency: a systematic review of severe pandemic influenza management. Crit Care Med. 2013;41:1345-52.

15. Hsu J, Santesso N, Mustafa R, Brozek J, Chen YL, Hopkins JP, Cheung A, Hovhannisyan G, Ivanova L, Flottorp SA, Saeterdal I, Wong AD, Tian J, Uyeki TM, Akl EA, Alonso-Coello P, Smaill F, Schunemann HJ. Antivirals for treatment of influenza: a systematic review and meta-analysis of observational studies. Ann Intern Med. 2012;156:512-24.

16. Uno $Y$, Usui $T$, Soda K, Fujimoto $Y$, Takeuchi T, Ito H, Ito T, Yamaguchi T. The pathogenicity and host immune response associated with $\mathrm{H} 5 \mathrm{~N} 1$ highly pathogenic avian influenza virus in quail. J Vet Med Sci. 2013;75:451-7.

17. Ramos I, Fernandez-Sesma A. Innate immunity to H5N1 influenza viruses in humans. Viruses. 2012;4:3363-88.

18. Ling MT, Tu W, Han Y, Mao H, Chong WP, Guan J, Liu M, Lam KT, Law HK, Peiris JS, Takahashi K, Lau YL. Mannose-binding lectin contributes to deleterious inflammatory response in pandemic H1N1 and avian H9N2 infection. J Infect Dis. 2012;205:44-53.

19. Viemann D, Schmolke M, Lueken A, Boergeling Y, Friesenhagen J, Wittkowski H, Ludwig S, Roth J. H5N1 virus activates signaling pathways in human endothelial cells resulting in a specific imbalanced inflammatory response. J Immunol. 2011;186:164-73.

20. Warnke PH, Humpe A, Strunk D, Stephens S, Warnke F, Wiltfang J, Schallmoser K, Alamein M, Bourke R, Heiner P, Liu Q. A clinically-feasible protocol for using human platelet lysate and mesenchymal stem cells in regenerative therapies. J Craniomaxillofac Surg. 2013;41:153-61.

21. Schnerch A, Lee JB, Graham M, Guezguez B, Bhatia M. Human embryonic stem cell-derived hematopoietic cells maintain core epigenetic machinery of the polycomb group/trithorax group complexes distinctly from functional adult hematopoietic stem cells. Stem Cells Dev. 2013;22:73-89.

22. Toonkel RL, JM Hare, MA Matthay, MK Glassberg. Mesenchymal stem cells and idiopathic pulmonary fibrosis. Potential for clinical testing. Am J Respir Crit Care Med. 2013:188:133-40.

23. Waszak P, Alphonse R, Vadivel A, Ionescu L, Eaton F, Thebaud B. Preconditioning enhances the paracrine effect of mesenchymal stem cells in preventing oxygen-induced neonatal lung injury in rats. Stem Cells Dev. 2012;21:2789-97.

24. Wang N, Li Q, Zhang L, Lin H, Hu J, Li D, Shi S, Cui S, Zhou J, Ji J, Wan J, Cai G, Chen X. Mesenchymal stem cells attenuate peritoneal injury through secretion of TSG-6. PLoS One. 2012;7:e43768.

25. Maria Spaggiari G, Moretta L. Cellular and molecular interactions of mesenchymal stem cells in innate immunity. Immunol Cell Biol. 2013;91:27-31.

26. Reddy BY, Xu DS, Hantash BM. Mesenchymal stem cells as immunomodulator therapies for immune-mediated systemic dermatoses. Stem Cells Dev. 2012;21:352-62.

27. Gharaee-Kermani M, Gyetko MR, Hu B, Phan SH. New insights into the pathogenesis and treatment of idiopathic pulmonary fibrosis: a potential role for stem cells in the lung parenchyma and implications for therapy. Pharm Res. 2007;24:819-41.

28. Xia J, Zhang H, Sun B, Yang R, He H, Zhan Q. Spontaneous breathing with biphasic positive airway pressure attenuates lung injury in hydrochloric acidinduced acute respiratory distress syndrome. Anesthesiology. 2014;120:1441-9.

29. Butt $A M$, Siddique $S$, Idrees M, Tong Y. Avian influenza A (H9N2): computational molecular analysis and phylogenetic characterization of viral surface proteins isolated between 1997 and 2009 from the human population. Virol J. 2010;7:319.

30. Ashour MM, Khatab AM, El-Folly RF, Amer WA. Clinical features of avian influenza in Egyptian patients. J Egypt Soc Parasitol. 2012;42:385-96.

31. Li C, Bankhead 3rd A, Eisfeld AJ, Hatta Y, Jeng S, Chang JH, Aicher LD, Proll S, Ellis AL, Law GL, Waters KM, Neumann G, Katze MG, McWeeney S, Kawaoka Y. Host regulatory network response to infection with highly pathogenic H5N1 avian influenza virus. J Virol. 2011;85:10955-67.

32. Cilloniz C, Shinya K, Peng X, Korth MJ, Proll SC, Aicher LD, Carter VS, Chang $J$ H, Kobasa D, Feldmann F, Strong JE, Feldmann H, Kawaoka Y, Katze MG. Lethal influenza virus infection in macaques is associated with early dysregulation of inflammatory related genes. PLoS Pathog. 2009:5:e1000604.
33. Zeng H, Pappas C, Belser JA, Houser KV, Zhong W, Wadford DA, Stevens T, Balczon R, Katz JM, Tumpey TM. Human pulmonary microvascular endothelial cells support productive replication of highly pathogenic avian influenza viruses: possible involvement in the pathogenesis of human H5N1 virus infection. J Virol. 2012;86:667-78.

34. Ferreira HL, Pirlot JF, Reynard F, van den Berg T, Bublot M, Lambrecht B. Immune responses and protection against $\mathrm{H} 5 \mathrm{~N} 1$ highly pathogenic avian influenza virus induced by the Newcastle disease virus $\mathrm{H} 5$ vaccine in ducks. Avian Dis. 2012;56:940-8

35. Filali M, Liu X, Cheng N, Abbott D, Leontiev V, Engelhardt JF. Mechanisms of submucosal gland morphogenesis in the airway. Novartis Found Symp. 2002;248:38-45. discussion -50, 277-82.

36. Kim DW, Staples M, Shinozuka K, Pantcheva P, Kang SD, Borlongan CV. Wharton's jelly-derived mesenchymal stem cells: phenotypic characterization and optimizing their therapeutic potential for clinical applications. Int J Mol Sci. 2013;14:11692-712.

37. Xue J, Li X, Lu Y, Gan L, Zhou L, Wang Y, Lan J, Liu S, Sun L, Jia L, Mo X, Li J. Gene-modified mesenchymal stem cells protect against radiation-induced lung injury. Mol Ther. 2013;21:456-65.

38. Toonkel RL, Hare JM, Matthay MA, Glassberg MK. Mesenchymal stem cells and idiopathic pulmonary fibrosis. Potential for clinical testing. Am J Respir Crit Care Med. 2013;188:133-40.

39. Mei SH, McCarter SD, Deng Y, Parker CH, Liles WC, Stewart DJ. Prevention of LPS-induced acute lung injury in mice by mesenchymal stem cells overexpressing angiopoietin 1. PLoS Med. 2007:4:e269.

40. Zhang S, Wang Y, Mao JH, Hsieh D, Kim IJ, Hu LM, Xu Z, Long H, Jablons DM, You L. Inhibition of CK2alpha down-regulates Hedgehog/Gli signaling leading to a reduction of a stem-like side population in human lung cancer cells. PLoS One. 2012;7:e38996.

41. Alphonse RS, Rajabali S, Thebaud B. Lung injury in preterm neonates: the role and therapeutic potential of stem cells. Antioxid Redox Signal. 2012;17:1013-40.

42. Nemeth K, Leelahavanichkul A, Yuen PS, Mayer B, Parmelee A, Doi K, Robey PG, Leelahavanichkul K, Koller BH, Brown JM, Hu X, Jelinek I, Star RA, Mezey E. Bone marrow stromal cells attenuate sepsis via prostaglandin $E(2)-$ dependent reprogramming of host macrophages to increase their interleukin-10 production. Nat Med. 2009;15:42-9.

43. Puneet $P$, Moochhala $S$, Bhatia M. Chemokines in acute respiratory distress syndrome. Am J Physiol Lung Cell Mol Physiol. 2005;288:L3-15.

44. Lam WY, Yeung AC, Ngai KL, Li MS, To KF, Tsui SK, Chan PK. Effect of avian influenza A H5N1 infection on the expression of microRNA-141 in human respiratory epithelial cells. BMC Microbiol. 2013;13:104.

45. Wang Y, Sun Z, Qiu X, Li Y, Qin J, Han X. Roles of Wnt/beta-catenin signaling in epithelial differentiation of mesenchymal stem cells. Biochem Biophys Res Commun. 2009:390:1309-14.

\section{Submit your next manuscript to BioMed Central and we will help you at every step:}

- We accept pre-submission inquiries

- Our selector tool helps you to find the most relevant journal

- We provide round the clock customer support

- Convenient online submission

- Thorough peer review

- Inclusion in PubMed and all major indexing services

- Maximum visibility for your research

Submit your manuscript at www.biomedcentral.com/submit
) Biomed Central 